\title{
Purification and characterization of a gastrointestinal tract epithelial receptor for the adhesion factor of Lactobacillus
}

\author{
Xue-Yan Lin, Zhong-Hua Wang, ${ }^{*}$ Zhong-Xiang Niu*, Jun Peng \\ College of Animal Science \& Technology, Shandong Agriculture University, Tai'an, China \\ Email: linxueyan@sdau.edu.cn, ${ }^{*}$ zhwang@,sdau.edu.cn, ${ }^{*}$ zxniu@sdau.edu.cn
}

Received 8 February 2012; revised 25 March 2012; accepted 15 April 2012

\begin{abstract}
An epithelial receptor for the Lactobacillus surface adhesion factor was isolated and purified from mucus of the gastrointestinal tract of SPF chickens, using chromatography. The purified protein was analyzed with discontinuous, native gel electrophoresis and binding assay with cultured intestinal epithelial cells. A single band was obtained after purification. The molecular weight of this band was about $60 \mathrm{KDa}$. The purified protein inhibited the attachment of Lactobacillus to intestinal epithelial cells, suggesting that it is the gastrointestinal receptor for the surface adhesion factor of Lactobacillus.
\end{abstract}

Keywords: Lactobacillus; Adhesion Protein; Intestinal Epithelial Cell; Receptor

\section{INTRODUCTION}

Under normal physiological conditions, a large amount of bacteria are attached to the surface of gastrointestinal epithelial cells in animals, forming a bacterial biofilm [1-3]. The biofilm is very important for animal immunity, defense, and nutrient absorption. When animals suffer from diarrheal diseases, the normal adhesion is destroyed, causing disturbance of gastrointestinal microflora. The adhesion of normal bacteria to epithelium is mediated by the interaction between adhesion factor from the epithelial cells and the receptor from the surface of normal bacteria [4-6]. Using advanced protein isolation, purification and identification technologies, we successfully isolated from the gastrointestinal tract of SPF chickens an epithelial receptor, determined the molecular weight and adhesive activity. These results provided resources for studying interactions between normal microflora and the host, and provided valuable data for the development of animal microecology. The existence and

\footnotetext{
"Corresponding authors.
}

activity of adhering factors in normal bacteria (for example Lactobacilli) await further study.

\section{MATERIALS AND METHODS}

\subsection{Materials}

\subsubsection{Intestinal Epithelial Cells}

$\mathrm{CaCo}-2$ cells were purchased from Shanghai Institute of Cell Biology.

Cell culture: cells were cultured with DMEM (pH 7.0 - 7.2) supplemented with $10 \%$ calf serum, $1000 \mathrm{IU} / \mathrm{L}$ penicillin, $100 \mu \mathrm{g} / \mathrm{L}$ streptomycin, in an incubator with $\mathrm{CO}_{2}$ maintained at $5 \%$. When sufficiently attached to the culture flask, cells were washed with phosphate buffered solution ( $\mathrm{pH} 7.4)$, digested with digestion solution $(0.02 \%$ EDTA:D-Hanks solution $=10: 1$, without $\mathrm{Ca}^{2+}$ and $\mathrm{Mg}^{2+}$ ) for 20 - $30 \mathrm{~min}$. The digestion was stopped before cells detaching from the culture flask by inverting the flask for 3 min. Digestion solution was removed, and 10\% DMEM (DMEM containing 10\% serum) was added to the flask, mixed thoroughly, split to new flasks.

\subsubsection{DMEM Medium}

Medium was purchased from Invitrogen. Calf serum was purchased from Beijing Dingguo Biotechnology Inc.

\subsubsection{Lactobacillus}

Lactobacillus (SDnA) was isolated from SPF chicken (purchased from Shandong Poultry Institute) by Microbiology Laboratory of SAU.

\subsubsection{Protein Chromatography System}

REC5004V $\mathrm{V}_{18}$ system was purchased from Phamarcia (Sweden).

\subsubsection{Spectrophotometer}

UV-2000 spectrophotometer was purchased from Unico (Shanghai) Instrument Inc. 


\subsection{Methods}

\subsubsection{Sample Collection and Treatment}

Ten SPF chickens of 130 days old were sacrificed after fasting for $8-10 \mathrm{~h}$. Mucus $(10 \mathrm{ml})$ from the crop and small intestine was collected by scraping the surface. Mucus was diluted with saline (1:2), spun at $5000 \mathrm{rpm}$, $4^{\circ} \mathrm{C}$ for $15 \mathrm{~min}$. Supernatant was saved for future use.

\subsubsection{Extraction of Receptor Protein}

Sansonetti PJ (1991) indicated that molecular weight of the receptor of Shigella flexneri virulence is about 40 $60 \mathrm{kDa}$. Thus, the $30 \%$ saturated ammonium sulfate method was used to extract the protein. The extracted precipitate was dissolved in $3 \mathrm{ml}$ of $0.01 \mathrm{~mol} / \mathrm{L}$ ( $\mathrm{pH} 7.4$ ) phosphate buffered solution, dialyzed in phosphate buffered solution to remove $\left(\mathrm{NH}_{4}\right)_{2} \mathrm{SO}_{4}$, concentrated with PEG-6000 until $1 \mathrm{ml}$. Protein concentration was calculated after OD260 and OD280 measurement. Samples were stored frozen until use.

\subsubsection{Purification of Receptor Protein (Sephadex Chromatography)}

Sephadex 50 was swollen in water, mixed and packed in a column $(1.2 \times 100 \mathrm{~cm})$. After equilibrating the column with phosphate buffered solution $(0.01 \mathrm{~mol} / \mathrm{L}, \mathrm{pH} 7.2)$, the receptor protein crude extract $(1 \mathrm{ml})$ was loaded, then, eluted with phosphate buffered solution $(0.01 \mathrm{~mol} / \mathrm{L}, \mathrm{pH}$ $7.2)$ at $0.2 \mathrm{ml} / \mathrm{min}$. Each peak $(280 \mathrm{~nm})$ was collected separately and frozen until use.

\subsubsection{Identification of Receptor Protein}

1) Discontinuous polyacrylamide gel electrophoresis analysis was performed according to Wang J. Z. (2002) to analyze the products of crude extract (by ammonium sulfate method) and fine extract (sephadex 50 method).

2) Adhesion and Adhesion Inhibition Test: Coverslips were put in 24-well culture plates, then $\mathrm{CaCo}-2$ cells were seeded in the plates and cultured for $2-3$ days. 200 $\mu \mathrm{l}$ of Lactobacillus cultured for $48 \mathrm{~h}$ were added to each well (3 parallel samples), incubated for $24 \mathrm{~h}$. Another plate was treated with $200 \mu \mathrm{l}$ Lactobacillus (prepared by incubating $1000 \mu \mathrm{l}$ culture with 200 crude and fine extracts separately) for $24 \mathrm{~h}$ at $37^{\circ} \mathrm{C}$ in a incubator, each with 3 parallel samples. Then, coverslips were taken out of the plate, washed with phosphate buffered solution (pH 7.4) several times, dried naturally, fixed with methanol, stained with Gram stain, examined under microscope (examining 50 cells, counting the number of Lactobacillus attached to each cell).

\subsubsection{Statistics}

Between treatment were assessed utilizing with the ANOVA procedure and Duncan's Multiple Range Test was used for multiple comparisons analyze the treatment effects adherence to the cells.

\section{RESULTS}

\subsection{Adhesion Factor (Receptor Protein) Extraction}

A total of $10 \mathrm{ml}$ of mucus was collected from the gastrointestinal tract of 10 adult SPF chickens. Epithelial adhesion factor was extracted with $30 \%$ saturated ammonium sulfate method, resulting in $1 \mathrm{ml}$ receptor protein $(24$ $\mathrm{mg} / \mathrm{ml}$ ).

\subsection{Purification of Adhesion Factor (Receptor Protein)}

Three clear peaks appeared after sephadex-50 chromatography (Figure 1). Protein solution $(5 \mathrm{ml})$ was collected from each peak.

\subsection{Identification of Adhesion Factor (Receptor Protein)}

Electrophoresis was performed to analyze the crude (30\% ammonium sulfate) and fine (sephadex 50 chromatography) extracts of adhesion factor (receptor protein). Results were shown in Figures 2 and 3.

\subsection{Adhesion and Adhesion Inhibition Test}

1) How the crude extract influences the adhesion of Lactobacillus to intestine epithelial cells was shown in Table 1.

Results in Table 1 suggest that the 30\% saturated ammonium sulfate extract contains the adhesion factor (receptor protein). This provides the basis for further purification.

2) Table 2 shows the effect of collected 3 peaks after sephadex chromatography on the adhesion of Lactobacillus (Figures $\mathbf{4}$ and 5).

Table 2 shows that the three elution preparations displayed large differences in their influence on the adhesion of lactobacillus. Peak 2 had the best effect, suggesting this peak contained the epithelial receptor for adhesion factor (receptor protein).

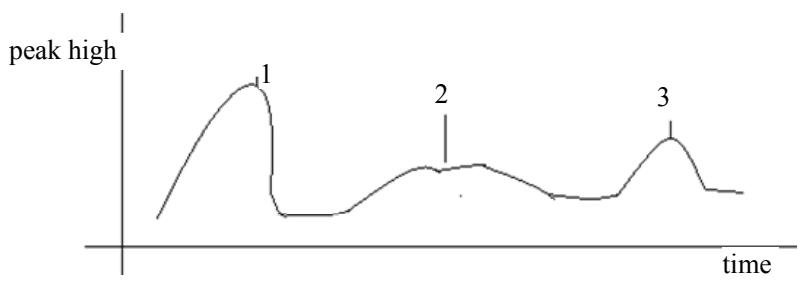

Figure 1. Chromatography profile of receptor protein for Lactobacillus extracted from intestinal epithelium. 


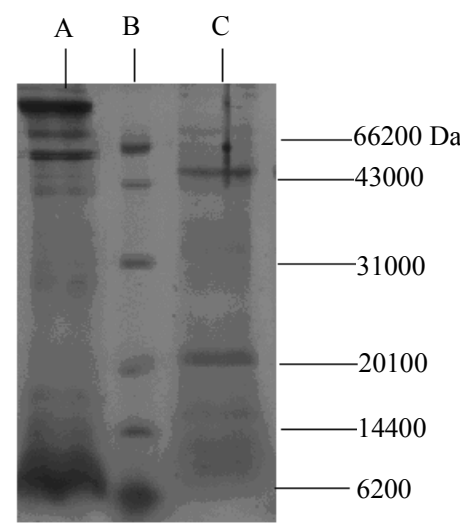

Figure 2. Electrophoresis of crude extract (30\% ammonium sulfate) of epithelial adhesion factor (receptor protein). A. Small intestine mucosal receptor protein from 130 days old SPF chickens. B. molecular weight marker. C. crop mucosal receptor from 130 days old SPF chickens.

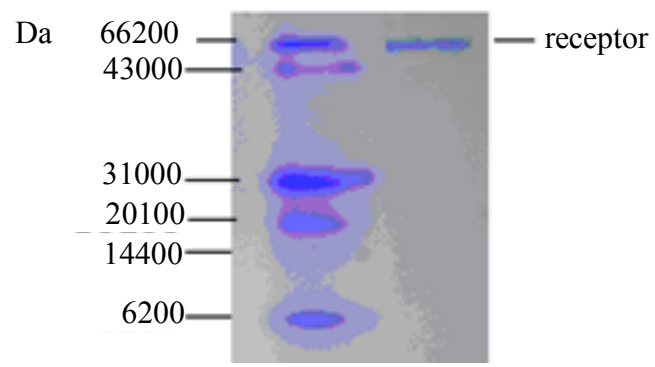

Figure 3. Native gel electrophoresis of the fine extracts (sephadex Chromatography) of intestinal epithelial receptor protein.

Table 1. Effect of crude extract of epithelial receptor on the adhesion of Lactobacillus to intestinal epithelial cells.

\begin{tabular}{cc}
\hline Treatment & $\begin{array}{c}\text { Number of Lactobacillus } \\
\text { adhered (entries/cell) }\end{array}$ \\
\hline $30 \%\left(\mathrm{NH}_{4}\right)_{2} \mathrm{SO}_{4}$ & $4.00 \pm 0.51^{\mathrm{a}}$ \\
Control & $18.70 \pm 1.98^{\mathrm{b}}$ \\
\hline
\end{tabular}

Table 2. Effect of protein preparations purified with sephadex chromatography on the adhesion of Lactobacillus to intestinal epithelial cells.

\begin{tabular}{cc}
\hline Peak & $\begin{array}{c}\text { Number of Lactobacillus } \\
\text { adhered (entries/cell) }\end{array}$ \\
\hline 1 & $18.87 \pm 1.78^{\mathrm{a}}$ \\
2 & $5.00 \pm 0.98^{\mathrm{b}}$ \\
3 & $19.45 \pm 1.25^{\mathrm{a}}$ \\
Control & $21.00 \pm 1.76^{\mathrm{a}}$ \\
\hline
\end{tabular}

\section{DISCUSSION}

Molecular weights of adhesion molecules from pathogenic bacteria and their receptor in intestinal epithelium

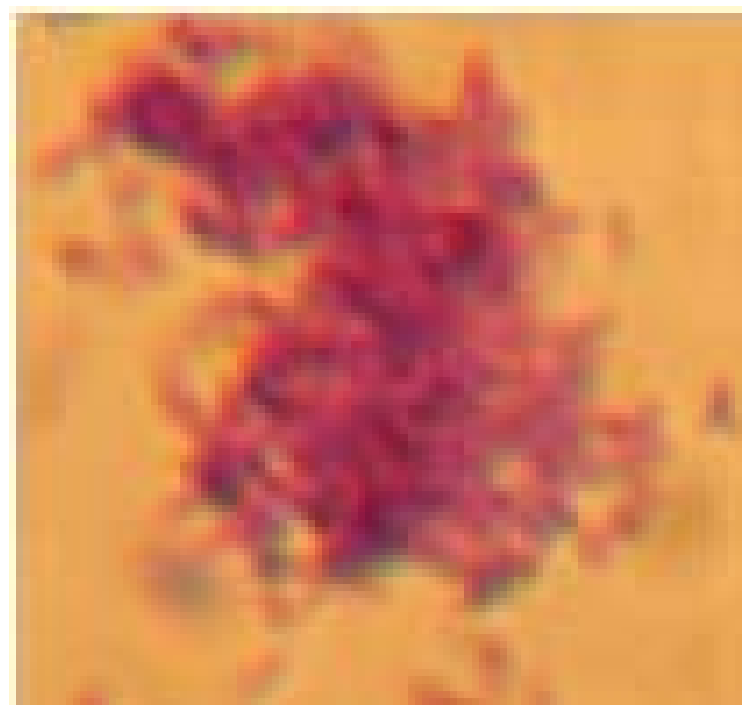

Figure 4. Adhesion of Lactobacillus to CaCo-2 cells.

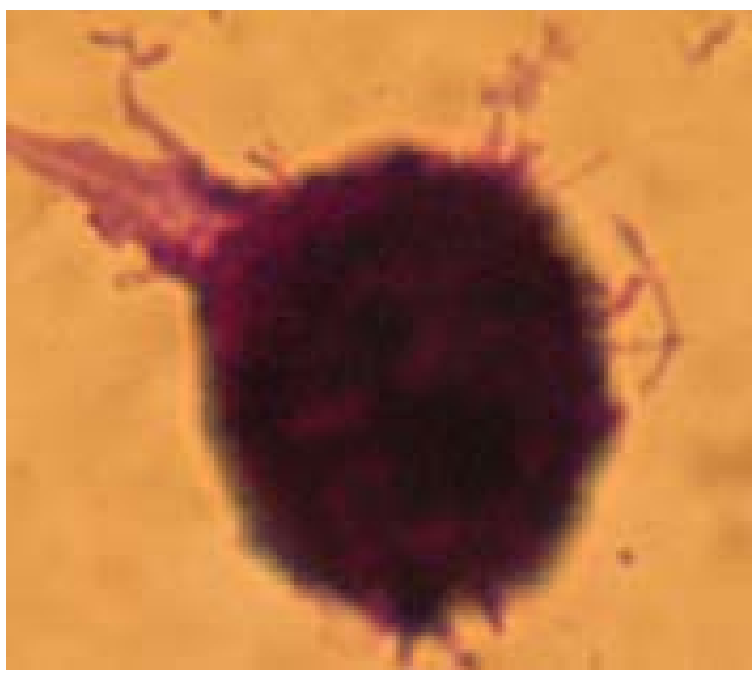

Figure 5. Elution peak 2 decreased the number of Lactobacillus adhered to intestinal epithelial cells ( $\mathrm{CaCo}-2$ cell).

have been reported. Using hydrochloric acid SDS polyacrylamide gel electrophoresis method, John (1991) analyzed the receptor protein from swine mucus for $E$. coli K12 (K88ab) and found the receptor was a $40-42$ kDa complex. Sansonetti (1991) demonstrated that receptors for E. coli on intestinal epithelium were 62 and $48 \mathrm{kDa}$ [7]. There are no data available for intestinal epithelial receptors of the beneficial bacterium Lactobacillus. Results from our study indicate that the receptor in the chicken for lactobacillus is $60 \mathrm{kDa}$. In addition, Sellwood R. (1980) showed that monosaccharide and polysaccharides can inhibit the adhesion of K88 antigen to intestine epithelium [7]. This area needs further study [8-10].

There are many receptors in intestinal epithelial cells for normal and pathogenic bacteria. Some of the recap- 
tors have similar molecular weight. In the current study, mucus from SPF chicken was used, which excluded the interference of receptors for pathogenic bacteria. In addition, the identification and purification of epithelial receptor for Lactobacillus were performed by the method of using a purified Lactobacillus adhesion protein and cell combination. This method is relatively good.

Studies on the molecular weight of receptors for normal microflora are important for the improvement of adhesion of normal bacteria and the mechanic investigation. Knowing the genes for adhesion proteins, the extracted proteins can be further analyzed by expression. It is necessary in the future to determine the structure, sequence and expression of receptor proteins.

Previous protein purification requires a cumbersome combination of molecular sieve and ion exchange chromatography. Even though, results are not ideal. In the current study, columns for isolation of protein of small molecular range were used to isolated proteins of larger molecular proteins. This method showed a good separation.

\section{CONCLUSION}

The intestinal epithelial receptor for the Lactobacillus surface adhesion factor was isolated and purified using chromatography and analyzed with discontinuous native polyacrylamide gel electrophoresis technology. The molecular weight was determined to be $60 \mathrm{KDa}$.

\section{ACKNOWLEDGEMENTS}

This work was supported by the ministry of Agriculture of China: the earmarked fund for Modern Agro-industry Technology Research System of China and natural science fund of China (31072050).

\section{REFERENCES}

[1] Wang, J.Z. and Fan, M. (2002) Protein technology. Science Press, Beijing.
[2] Zheng, Y.J., Pan, L.J. and Wang, L.S. (1999) Purify adhension from biobacillus. Chinese Journal of Mocrobioloy and Immunology, 19, 196.

[3] Zhao, B. and He, S.J. (2002) Microbiological experiment. Beijing Science Press, Beijing.

[4] Bernet, M.F., Brassart, D. and Neeser, J.R. (1994) Lactobacillus acidophilus LA 1 binds to Cultured intestinal cell Lines and inhibits cell attachment cell invasion by enterovirulen. Bacteria Gut, 35, 483-489.

[5] Henriksson, A. and Conway, P.L. (1996) Adhesion of Lactobacillus fermentum 104-S to porcine stomach mucus. Current Microbiology, 33, 31-34. doi:10.1007/s002849900069

[6] Turner, M.S., Peter, T. and Louisem, H. (1997) Identification and characterization of a basic cell surface-located protein from Lactobacillus fermentum BR11. Journal of Bacteriology, 179, 3310-3316.

[7] Sansonetti, P.J. (1991) Molecular and cellular bases of Shigella flexneri virulence. Bulletin of the National Academy of Medicine, 175, 803-809.

[8] Shandong Agriculture University (2002) Biochemistry and molecular biological test technology. Shandong Publishing Company, Tai'an.

[9] Sellwood, R. (1980) The interaction of the K88 antigen with porcine intestinal epithelial cell brush borders. Biochimica et Biophysica Acta, 632, 326-335. doi:10.1016/0304-4165(80)90090-2

[10] Takahiro, T., Ritva, V. and Benita, W. (1995) A collagen-binding s-layer protein in Lactobacillus crispatus. Applied and Environmental Microbiology, 61, 2467-2471. 